\title{
A PROCEDURE TO IMPORT A COMPLEX GEOMETRY MODEL OF A HERITAGE BUILDING INTO BIM FOR ADVANCED ARCHITECTURAL REPRESENTATIONS
}

\author{
E. Acosta ${ }^{1}$ F. Spettu ${ }^{2}$ F. Fiorillo ${ }^{2}$ \\ ${ }^{1}$ High Technical School of Architecture, University of Seville, Seville, Spain, eduacosta@us.es \\ ${ }^{2}$ ABC Department, Politecnico di Milano, Milano, Italy, (franco.spettu, fausta.fiorillo)@polimi.it
}

Commission II

KEY WORDS: NURBS, 3D modelling, point cloud, Scan-to-BIM, Cultural Heritage, complex geometries.

\begin{abstract}
:
The aim of this communication is to present the advantages and disadvantages of a Scan-to-BIM process applied to a heritage building in order to obtain advanced technical drawings to be used in the analysis and illustration of the project. The whole process described includes: the survey planification and data acquisition with a Terrestrial Laser Scanner; the processing and cleaning of the point cloud; the 3D mathematical modelling; a proposal for semi-automatic modelling of organic elements; and the import of the final model into a BIM environment. Rhinoceros (McNeel) and Revit (Autodesk) are the main programs used. The crucial aspect of this workflow is found at the moment of importing the geometrical model into Revit, having to accommodate the criteria of this program in terms of tolerances, geometric structure of the solids, incompatibilities with NURBS libraries, etc. The result is a BIM model divided into families and subcategories where visual attributes can be assigned per element, parameterized and other visual information can be added (orthophotographs, wireframe analysis drawings, etc.). In other words, a 3D model from which highly configurable advanced representations (plans, vertical sections, perspectives, isometric exploded view, etc.) can be obtained and with which to generate analyses from the field of Architectural Graphic Expression.
\end{abstract}

\section{INTRODUCTION}

Our objective is to create an accurate model of a geometrically complex building, as heritage ones usually are, from a digital survey to obtain analytical architectural drawings, exploring the visualization possibilities offered by BIM environment.

This paper follows a working methodology that, starting from a point cloud of a building, allows the rigorous recreation of its ideal geometry (therefore, avoiding all constructive inaccuracies: deformations, later additions, etc.), divided into its constitutive elements, in modelling software, and the correct import of the final reconstruction into BIM environment.

Nowadays, most of the processes for creating Heritage-BIM models involve the use of commercial software. Autodesk Revit is among the best known and most used. This type of program allows the generation of a three-dimensional model, rich in information and parametric, but it also offers great possibilities for the analytic visualisation of the model and, therefore, the production of technical drawings (Maietti and Zattini, 2019). However, the modelling tools offered by Revit were considered not suitable for the purpose in terms of speed of the workflow and accuracy of the final output. This software is more performative and optimized to model and import standardized elements derived from new construction, which clashes with the "heterogeneous, complex, and irregular characteristics and morphologies of heritage buildings that are not represented in the BIM software libraries" (Fassi et al., 2015). In the case where an accurate and less time-consuming modelling of the analyzed building is required, it is necessary to model the building in auxiliary software and subsequently integrate the resulting model into the BIM program. The import procedure for complex and articulated geometries is far from being seamless and may occur that some geometries are not recognized, and then transformed or rejected by Revit.

\section{RELATED WORK}

There are numerous publications by different authors that deal with the limitations of BIM parametric software for modelling non-standard architectural objects (López et al., 2018). These authors typically use one of the following two procedural approaches. The first is to model directly in BIM environment, either by using its existing libraries for simple shapes or limited free-form tools for more complex elements. The second procedure is to model the building in another CAD software with more advanced and precise drawings tools and then import it into BIM. Given the complexity of our model, we have opted for the latter procedure.

The crucial moment in this process is to import the 3D model into Revit. Rhinoceros is a software that works with Non-Uniform Rational B-Splines (NURBS). Revit also works with NURBS; however, its NURBS library (Open-NURBS) is outdated (Davidson and Iran-Nejad, 2020), causing various problems during the import.

Some authors propose exporting the model in a format compatible with Revit, such as ACIS SAT (3D CAD), DXF or IFC (Baik et al., 2014; Banfi et al., 2017; Ferreyra et al., 2021; Barba et al., 2021). However, all of these formats can involve a possible source of incompatibilities, such as not always maintaining the geometry, the division into elements or the impossibility of adding information to the BIM model (Tommasi and Achille, 2017).

As of March 2021, Rhinoceros version 7 (Rhinoceros Development Team, 2021) includes a plugin named "Rhino.inside.Revit" that runs the CAD program in Revit environment. This allows a bi-directional integration between the two programs so that it is possible to load the Rhino native format (3DM). In addition, it includes the possibility of using Grasshopper, a parametric-generative software that allows greater control when importing the model. This modelling 
experience suggests that this new method solves the problems of the previous methodologies (Pepe et al., 2021).

\section{CASE STUDY}

The church of Nuestra Señora de los Remedios (Figure 1) is located in the village of Iznalloz, a small town in southern Spain. During the 16th century, the town was an important transit point connecting the southeast of Spain with the upper half of the peninsula. It was also one of the towns responsible for supplying the capital of Granada with cereals, which meant that during the harvest season, the number of inhabitants was significant. For these reasons, the archbishop of Granada commissioned the construction of a large, grandiose church to showcase the wealth of Granada Church and to be able to accommodate both resident and seasonal population. It was designed by the Renaissance architect Diego Siloé (ca. 1490-1563): the master designer of churches in the province of Granada and author, among many other works, of the cathedral of Granada (Gómez-Moreno, 1988).
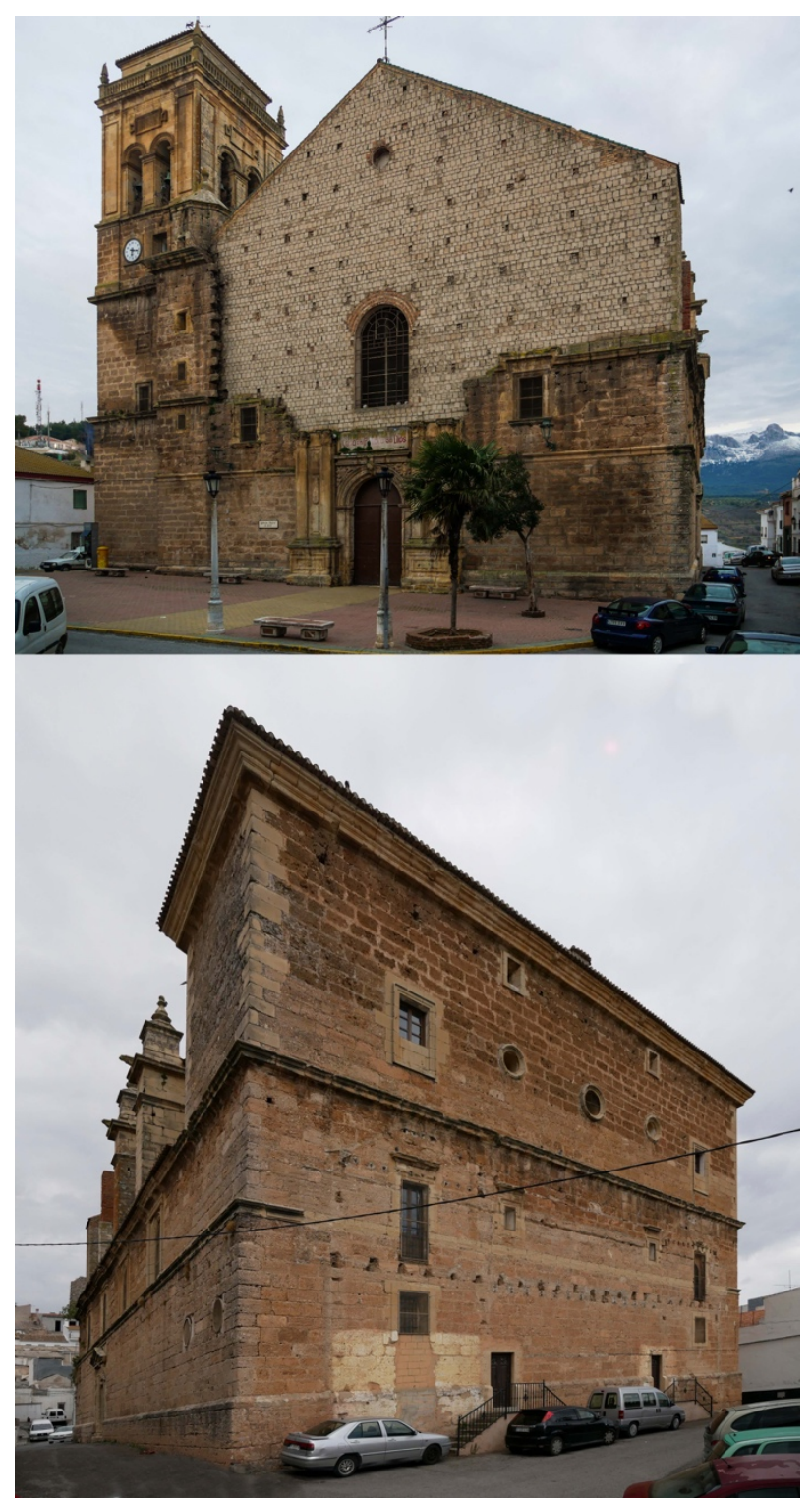

Figure 1. Main and back façade of the church of Nuestra Señora de los Remedios, Iznalloz.
The construction of the Iznalloz temple began in 1550, but due to the unrest of the Spanish context of the time, the work started to delay and finally, in the middle of the 17th century, the construction was abandoned. By this time, only half of the church, the chancel, had been completed, leaving the other half, the foot of the church, only up to the level of the main entablature. In the middle of the last century, it underwent several modifications, and the incomplete part was finally enclosed with a modern masonry structure and a metal roof.

If it had been completed, the church of Nuestra Señora de los Remedios would have been a temple of considerable dimensions and careful materiality. The ground plan forms a rectangle measuring $27 \mathrm{x} 40$ meters with three wide naves of four bays. On both sides, semicircular openings precede narrow chapels with Roman-style barrel vaults, and small decorations adorn the coffers. In the completed half of the church, the Hallenkirche design can be seen, with six vaults rising to the same height of 18 meters. At the front of the chancel opens a polygonal main chapel with a large, full-height, cut-out transverse arch, and on both sides, two fronts house an altarpiece and the prominent archbishop's coat-of-arms. Behind these, there are two sacristies, and above them, symmetrically, there are three rooms, all of which were designed on the outside as a palatial façade, making this building a rare example of a palace-church in Spain.

Constructively, Siloé designed a temple entirely of good-quality stone, which allowed very fine decorations to be carved. These can be found in the classical mouldings and ornamentation such as capitals, flowers, coats of arms, etc., scattered both inside and outside (Figure 2). This parish church was an ambitious project, both in terms of size and materiality, coinciding with a period of an economic boom in the archdiocese of Granada.

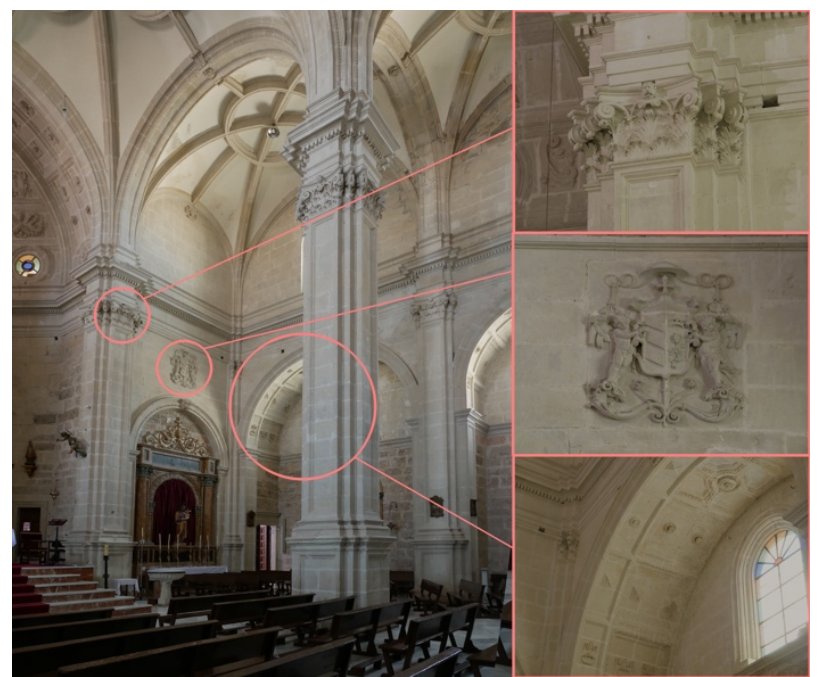

Figure 2. Interior of the church of Nuestra Señora de los Remedios, Iznalloz.

This work is part of a doctoral thesis on the church of Nuestra Señora de los Remedios de Iznalloz and the figure of the architect Diego Siloé, which is currently in progress. The research activity seeks to study the work from a spatial point of view: the conformation of space in terms of relations between architectural entities. At present, there is little information and studies on this temple. Nor is there any reliable planimetry of the church. For these reasons, a digital $3 \mathrm{D}$ reconstruction of the original project was proposed based on an accurate architectural survey of the current and real state of the church. 


\section{METHODOLOGY}

\subsection{Survey planification and data acquisition}

The general strategy for the church virtual reconstruction (Figure 3) consists of a variation of the Scan-to-BIM methodology (Rocha et al., 2020). This method is based on building surveying, with the chosen survey technique, and then modelling directly from the point cloud in a BIM program. Evidence suggests that the process is not as useful in the case of geometrically complex heritage buildings (Barazzetti et al., 2015; López et al., 2018).

The first step consisted of developing a strategy in relation to the subject to be represented and specifying the characteristics of these representations (such as the level of details and the scale of the graphic representation). To this end, the survey was based on three main steps: planification and choice of the more suitable survey system, data collection, and processing (Achille et al., 2015).

We decided to explore the representation capabilities offered by Building Information Modelling (BIM) software as a research objective. In our opinion, the advantages over CAD environments are clear and lie in the fact that BIM programs are aware that they draw three-dimensional elements with added information. This aspect allows greater control over sections and projections; great flexibility in representation and graphic analysis; and, to automatically update any changes on all drawings, resulting in a time reduction of the elaboration of the graphic representations (Maietti and Zattini, 2019).

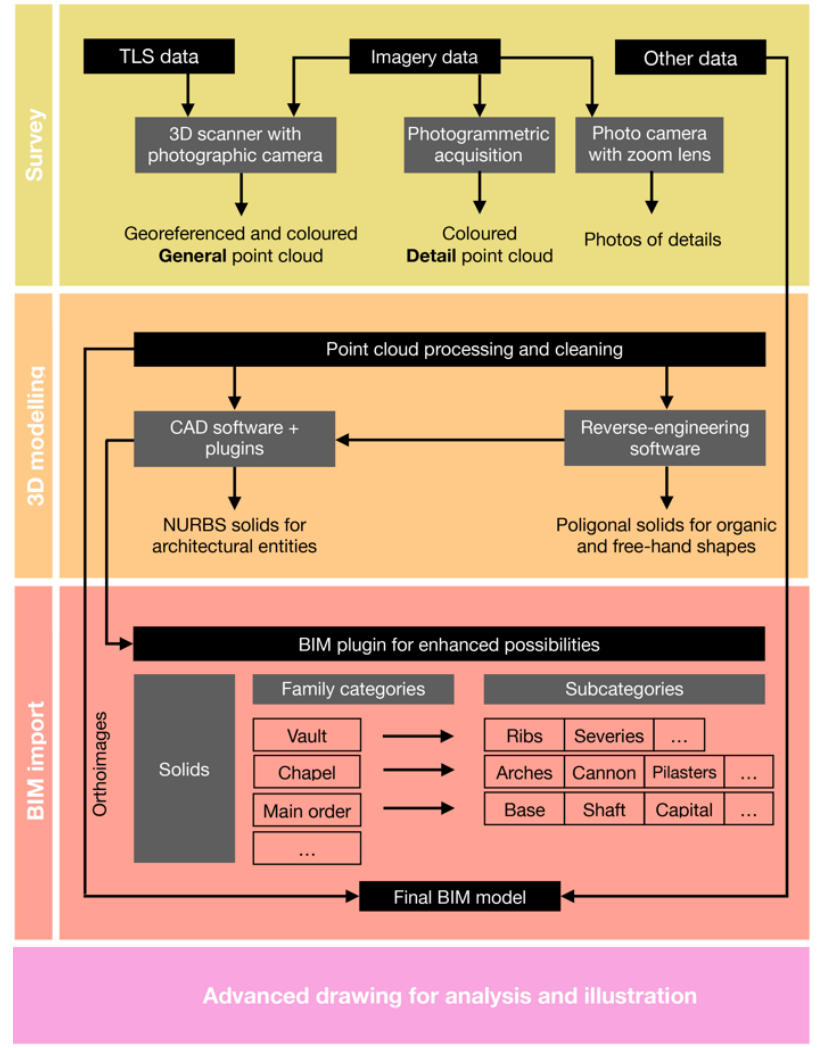

Figure 3. Concept map of the proposed methodology.

On the other hand, given the maximum scale of representation of the drawings of $1 / 125$, the accuracy of the scanning was decided in the function of the plotting error (Cardone, 2008). The standard tolerance that corresponds to the accuracy of the final technical drawings is assumed to be 2-3 times this value, thus having a reference value of $4 \mathrm{~cm}$.
Finally, the distance to Iznalloz, the difficulty of using the equipment, the required time and its cost were also taken into account when choosing the system. With all these variables, we chose to carry out a survey using a LiDAR scanner (Riegl VZ400i) with an embedded photographic system (Nikon D810 + Nikkor AF D 14/2.8) to colour the point cloud. The spatial resolution chosen was $2 \mathrm{~cm} @ 20 \mathrm{~m}$.

Unfortunately, it was impossible to enrich the data collection with aerial photogrammetry since the regulations in Spain for UAV flights are strict, both in urban exteriors and in the interiors of heritage buildings (Acosta and Moya, 2021), which meant more time and expense.

\subsection{Processing and cleaning the point cloud}

For operational purposes, the obtained point cloud (174M points, 5GB) was filtered and reduced. For these purposes, we used the free software CloudCompare. The strategy was as follows: the entire cloud was decimated; then the urban environment was cut down to obtain only the church; and finally, this section of the cloud was cleaned of superfluous points and exported, ready to work in the modelling software where the profiles of the elements to be drawn were to be obtained.

In cases where the point cloud reduction made it impossible to recognize the original geometry, for example, in some mouldings that required a great level of detail, the process has been different. The original cloud was not decimated, but only the element of interest was isolated, cleaned and exported.

Finally, a third case has followed a different procedure, the generation of orthoimages from the point cloud. For this elaboration, the cloud has been used without decimation and cleaned.

During the process of decimating the cloud, neither the minimum distance between points nor the final number of points in the resulting cloud were significant parameters. The main aim was to reduce the file size and, at the same time, to maintain recognizable shapes close enough to be able to draw them accurately. Therefore, the cloud was trimmed, and the number of points was reduced by $79 \%$, i.e. from a file size of more than 5000 MB to less than $500 \mathrm{MB}$.

File size has also been a problem when doing operations with the cloud: cloning, deleting points, etc., as CloudCompare loads all these modifications into RAM (main memory and dedicated graphics) and can end up overloading it. The problem was solved by combining three actions aimed at reducing the amount of memory used: first, looking at the cloud from afar, as in this way the program does not have to calculate each point, but one of the higher levels of the octree. In connection with this, in the display properties, the size at which the points are displayed was increased to a value of 16 , i.e. each point was displayed on the screen with a size of 16 pixels (CloudCompare Development Team, 2021). This way, there is no space to represent each individual point, as they overlap each other due to their size, so only a few of them are displayed. Thirdly and lastly, any colour representation (Scalar Field or RGB) was deactivated, as colouring the points also take up memory.

Once the necessary sectors had been isolated, the remaining step was to clean the cloud. The scanner can fail to capture data due to several factors: isolated points; measurement errors in reflective materials or in geometries that are difficult to interpret; problems at edges where the beam is separated; and so on (Alshawabkeh et al. 2021). All this results in unwanted points and errors on normal surfaces and curvature changes, i.e. point cloud registration failures.

Three successive procedures have been followed, also with the options offered by CloudCompare (PCL Contributors, 2021). 
First, the Statistical Outlier Removal (SOR) filter was used to remove points with a mean distance above the standard deviation. Second, points with a low density -dispersed- were removed by calculating the density of the volume and filtering the resulting Scalar Field in its lower range.

Third, the remaining unnecessary points were removed manually with the various selection tools.

With this, the cloud was ready to be imported into the modelling program, i.e. Rhinoceros (McNeel). Rhinoceros does not support the LAS format obtained from the point cloud processing, so we decided to switch to the E57 extension, an open format that stores data produced by $3 \mathrm{D}$ scanners and also image data from a digital camera (Huber, 2011).

\subsection{D modelling using NURBS geometry}

Our proposed process has been structured in the following main steps:

1. Divide the church into recognisable architectural entities.

2. Weigh up which of these elements are repeated and how much, if they have any variation.

3. Section the cloud to obtain the profile of the considered element.

4. Produce a surface from a NURBS "primitive" curve.

5. Produce a solid from this surface.

6. Export the model to the BIM environment.

The difference with the known Scan-to-BIM procedure is in step 4 and onwards. As we have stated in the objectives, our aim was to create a three-dimensional model of Siloé's ideal project for the church of Iznalloz in BIM software, from which to produce a series of advanced representations thanks to the advantages of these programs. In our experience, we have found that the reconstruction of complex geometries, such as the number of different cases we can find in a Renaissance building like this church, requires a multitude of modelling tools. Each of these tools is specific to create a curve, a surface, a solid, a specific shape whose shaping logic is different from others. For this reason, we decided to opt for a modelling software with a large repertoire of tools that worked with NURBS (Non-Uniform Rational B-Splines) geometry.

Rhinoceros was the program of choice, as in addition to working with point clouds and NURBS geometries, it offers a large selection of modelling tools and the possibility of expanding this repertoire through programming. These geometries have advantages because they allow us to produce complex surfaces and interact comfortably with less memory consumption (Valle et al., 1994).

On the other hand, since we decided to work with Revit, this model had to be composed of solids, not surfaces. The reason for this condition lies in the way Revit represents the section of these elements. When cutting a surface, for example, a capital, the program produces a section line, but it also displays the projected lines of the back of the element, that is, those lines that should be hidden, as we follow the convention that the inside of the sectioned elements should be represented with a solid fill. However, this does not happen when cutting a solid because cutting it produces section lines, while the only projected lines that appear are those external to the cut.

In the first and second steps, the elements to be modelled were established, which gave us a preview of the elements to be drawn and, at the same time, a working hierarchy. For example, one architectural entity is the main order, which is repeated throughout the interior space of the naves and the main chapel. This order has up to four variations depending on its position: free-standing, attached, in three quarters and in the corner. We have taken the isolated order as the basis for our drawings, and once the solid has been created, we have modified it to obtain the different variations thanks to the possibilities of operating with NURBS (Figure 4).

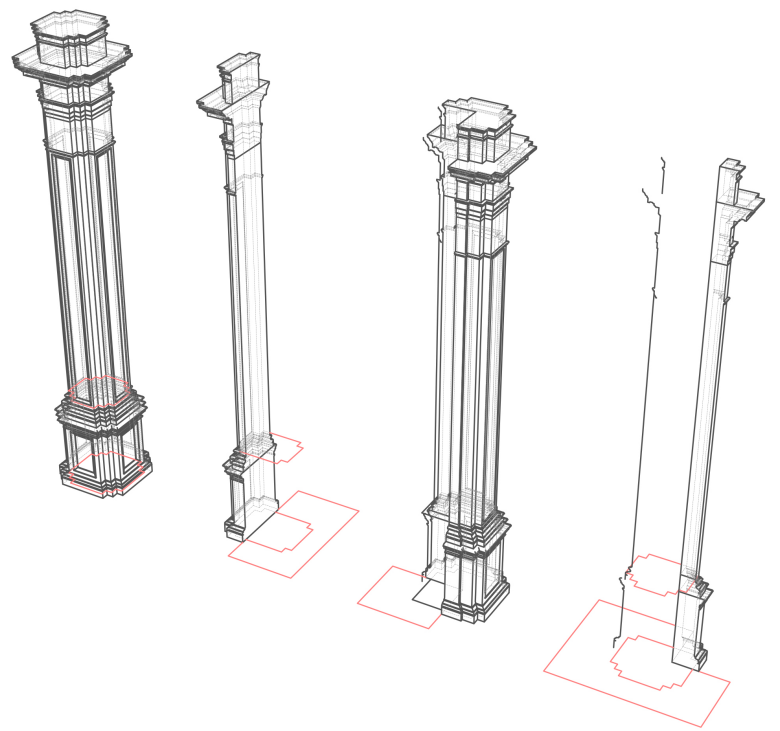

Figure 4. Model of the classical main order and its variations.

These architectural entities were divided into layers. This hierarchy is personal, and although there are proposals for semantic divisions within the field of heritage architecture (Apollinio et al., 2013), we believe that the characteristics of Spanish Renaissance architecture, and of Diego Siloé in particular, cannot be ascribed to a general theory. These proposed categories and subcategories are the result of our study of the architecture of the master and our own understanding of his way of thinking about these works.

The next step is the section of the point cloud. Rhinoceros is capable of working natively with point clouds; however, there are alternatives within the program that work better with these entities. This is the case of the free plugin "Cockroach" (Vestartas and Settimi, 2021) that allows greater control when sectioning point clouds. For the resolution of our cloud, we have found that $2 \mathrm{~cm}$ slice thickness produce sections with a sufficient density of points to recognize the profile of the element.

The church is quite regular, and there are no major problems with the layout or divergence of measurements. We know that Siloé designed his floor plans using the traditional metric of Castilian "varas" $(0.8359 \mathrm{~m})$ and "pies" $(0.2786 \mathrm{~m})$, while for vertical measurements, he used the order as a reference element. This was a common practice during the Italian Renaissance that Siloé put into practice when he returned from a study trip to Italy (Rosenthal, 1990). Indeed the measurements of the church are easily translatable into the Castilian unit of measurements, and in the regularised layout, we can see that the differences are of the order of $2-3 \%$.

It should be noted that the Revit tolerance is $0.1 \mathrm{~mm}$, i.e. everything that is subsequently imported into this program and has a thickness or length less than this amount will be excluded (Rhinoceros Development Team, 2021). For this reason, and before drawing the NURBS, it is necessary to match the tolerance of the drawing to the maximum tolerance of Revit. Once the most 
regular element has been sectioned, the resulting curves are drawn using B-Splines, taking this tolerance into account. In order to draw the profiles, it has also been necessary to use photographic data to see every detail accurately, especially in the small shapes that make the recesses, cornices and other moulded elements. The measurements of the final element have been adapted to the regularized measurements.

Once the primitive profile has been drawn, the surface is generated using the main modelling tools (Diara and Rinaudo, 2020). In most cases, these have been drawn with the same logic: one curve - generatrix - moving along another - directrix. For example, the classical order is fully defined by a profile - a vertical section - and a curve along which it moves - a horizontal section (Figure 4). The same procedure is correct for arches, windows, cornices and so on. However, the decorative elements follow freer forms.

To a certain extent, the drawing process of the physical building has followed the logic of this conformation. At the time of the erection of the parish church, the stone pieces were carved using a template (named "baivel"), which was placed along the stone block as it was being worked (Palacios, 2009). In the same way, our generator profile moves along the base of the element and produces the desired surface. However, this logic is not followed everywhere, for example, the severy is not a ruled surface, but its curvature adapts as it can to the imposition of the former and perpendicular arches. Therefore, the way of generating these surfaces has been different and coincides, curiously, with the fact that the severies are not made of stone but of brick.

The movement of the curves can generate a surface (polysurface) if the profile and/or the base are open curves or directly a solid (closed polysurface) if both the profile and the base are closed curves. In the first case, it is necessary to draw auxiliary surfaces to help close the solid, while in the second case, the method is more direct but more limiting. It is necessary to employ Boolean operations both to solve these cases and to obtain the variations of the architectural elements that are repeated. With these tools, solids can be added and subtracted so that by creating other auxiliary solids, the element can be "carved" until the desired shape is achieved.

\subsection{Semi-automatic modelling of organic elements}

The above method is valid for all those elements whose shaping logic follows the aforementioned example of the template with a geometrical layout but not for the decorations. These pieces of stone that appear on the interior have been carved freely, their shape depending on the skill of the carver. As a result, identical decorations have slight variations in their shape, dimensions, etc. This non-regular geometry is complex to model by the previous procedure and requires a long time to reach an approximate shape (Camagni et al., 2019). Therefore, a process that require less modelling and is moderately fast was proposed, i.e. a semiautomatic method such as the one based on reverse-engineering (Rossoni et al., 2019). This process turned out to be equally timeconsuming and complex in the end, so we finally discarded this option. However, we believe that the procedure deserves to be narrated as it has been part of the research of this work and has helped to understand the difficulties of modelling heritage buildings.

We have tried to follow a process similar to that of Pepe et al., 2021 and Camagni et al., 2019 for the modelling of these decorations. Nevertheless, this procedure is possible if a highdensity survey and correspondent point cloud is available. This has not been our case because these ornaments are located at a considerable height: the capitals are at 10 meters, and the rest above the entablature up to 16 meters, which has prevented us from carrying out photogrammetry or a specific high resolution laser data acquisition.

We have taken the case of one capital (Figure 5) as an example because it is the organic element that is at a lower height and, therefore, has two advantages over the rest of the decorations. First, being lower, the spatial resolution of the cloud was greater, and second, the laser scanner beam angle of incidence is less inclined, so there were fewer shadow areas. The chosen capital was clipped from the point cloud in CloudCompare and exported in E57 format, using the procedure mentioned above.

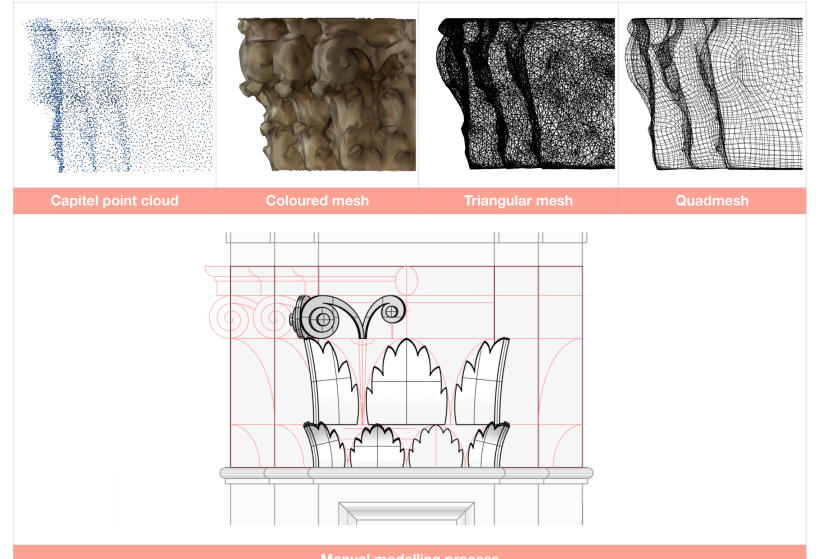

Figure 5. Semi-automatic and manual modelling of a capital.

The file was then imported into the surface processing software MeshLab. The workflow carried out has foreseen the following steps such as: the calculation of the normals, the transformation of the cloud into a polygon mesh by means of "Screened Poison Surface Reconstruction" and the artefact repair (mesh editing). This last step is essential since one of the main problems of this procedure is the appearance of unwanted geometries such as tunnels, isolated polygons or complex vertices (Salinas, 2014). Although the program offers several options to correct these mesh problems automatically, in our experience, it has been better to remove and correct them manually. In addition, it had to be taken into account that Revit does not allow the import of noncontinuous solids, so any openings had to be closed. The mesh obtained had 261,065 faces and 131,370 vertices.

The surface was then loaded into Geomagic software (3D Systems), where its surface was closed to create a watertight solid, and the number of faces was reduced. The mesh had to be decimated as in our experience Revit works with solids with an approximate limit of 150,000 faces. Again, mesh repair automation was used to fix any intricate geometry produced by these transformations.

Next, the triangular mesh was simplified into a mesh made up of quadrangular faces, as these allow for smoother geometries and reduce the file size. These operations were done in Rhinoceros using the "QuadRemesh" command.

On several occasions, the import process failed because the model still contained geometric problems. Therefore, it was necessary to return to Geomagic to retouch those problematic parts, restarting the modelling-repair process. However, both the quadrangular mesh and a later attempt to convert the mesh into a subdivisional surface (SubD) did not work in Revit.

\subsection{Importing the final model into the BIM environment}

The crucial step in this process is to import the final 3D model into Revit. As we have already mentioned, Revit has recently been equipped with the Rhino.Inside.Revit (RIR) plugin that allows running Rhinoceros in Revit's memory. In this way, most 
of the problems during the import are solved as there is deep integration between both software. However, this process introduces new problems, some of them probably due to the fact that this is a plugin of very recent development (it came out of the beta phase in Fall 2021).

There are currently several ways to import Rhino geometry into Revit using RIR (Rhinoceros Development Team, 2021):

- Direct import from the 3DM file

- Transformation of objects in DirectShapes

- Transformation of objects in Family instances

- Using Revit built-in System Families

We have opted for the one in between speed of import and control of the graphic result, a fundamental aspect for the elaboration of our advanced drawings. The method of family categories makes it possible to load each solid from the CAD program into one or more families, assigning each element a subcategory within the same family. In this way, the solids can be modified independently, allowing visual attributes to be assigned to each of them.

This procedure requires a series of preliminary steps. First, it is necessary that the solids are in different layers in Rhinoceros because from there, the categories of families and subcategories are created in Revit. Therefore, our Rhinoceros file was divided into many layers, one for each element or group of elements. For example, a rib of the vaults could be in the layer named "Vaults - Ribs" which in Revit was translated into the family "Vaults", subcategory "Ribs".

It is also important to know that the procedure to create a new family uses the existing templates in the program: walls, windows, conceptual masses, etc. These categories predefine a series of attributes to which the final shape will adhere, among them: the graphic properties. For example, not all categories allow to be sectioned by a cutting plane, such as "Wires" or "Furniture" (Autodesk Development Team, 2020); or the level of geometric complexity, the "Mass" and "Generic Model" families work in a special way since they temporarily duplicate the model to perform calculations such as volume (Autodesk Development Team, 2021), which can pose a problem in the computer memory. For these reasons we have chosen to create the families in the "Site" category, which can be cut and does not present the problems described above.

Another aspect to take into account is that Revit does not allow, from the project, to directly assign a cut fill to the subcategories. For example, it is not possible to change the default white fill to a black colour or a shade of grey. To achieve this, a material must be assigned to each subcategory, whose behavior when sectioned can be altered from the project. Thus, before importing the solids, different materials were created in the Revit project depending on the fill colour.

To finish with the preparations, it was necessary to make a qualitative analysis of the geometry to be imported, as Revit is sensitive to any type of geometric problem and tends to reject the model, as we saw with the example of the capital. In other words, we had to check that our solids did not have: naked edges, nonmanifold edges, edges shorter than $0.1 \mathrm{~mm}$. For this reason, we used the Grasshopper plugin. By means of a script, we searched for all these types of problems (Davidson and Iran-Nejad, 2020), and those surfaces with problems had to be repaired.

Once the pre-structure was ready, the next step was to program the import into Revit. In the absence of an options window to import the geometry by assigning families and subcategories, we had to resort again to the design of an algorithm script in Grasshopper (Figure 6). We used the sequence proposed in the Families method as a basis, but with some modifications to meet our criteria:
- We had the script search the file for all solids and filter them by layers.

- To each layer we assigned a material, which we had previously created with the cut fill properties.

- To the layer-material set we associated a subcategory and created the family component.

- We created as many families as architectural entities and assigned the corresponding subcategories.

- We added the families directly to a new project by specifying the same insertion coordinates for each family.

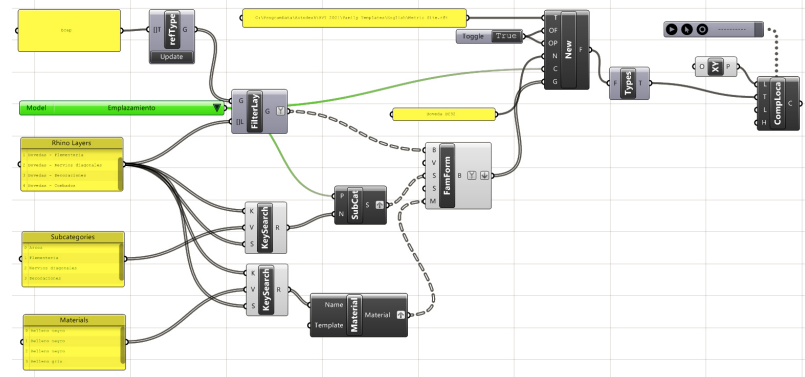

Figure 6. Grasshopper definitions for importing geometry from Rhinoceros into Revit.

Once this task was completed, the model was successfully imported into the BIM program, divided by elements and ready to assign different visual attributes to generate the plans and views for the study of the church (Figure 7).

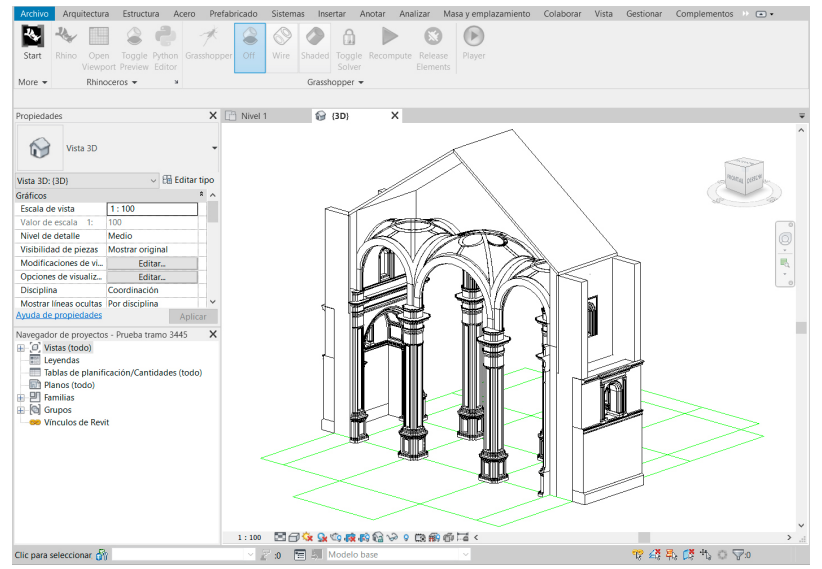

Figure 7. Partial model of the church imported into Revit.

\section{CONCLUSIONS}

BIM environments are a big step forward for heritage architecture professionals, guaranteeing a high level of performance in the results of graphic representations too. Thanks to advances in communication between different programs, especially with the help of plugins capable of loading in memory one inside the other, the process of BIM methodology has been simplified. However, the bulk work still falls on the manual modelling of all architectural elements, which in our case accounted for $80 \%$ of the activity involved.

The results show a trend towards reducing the process complexity and the modelling automation, with the proposal of 
complementary solutions such as reverse-engineering applied to architecture.

Regarding this last point, good data acquisition and high point density are fundamental for these surface reconstruction processes. For example, our capital lacked resolution, and the point cloud had too many shadow areas that the software filled in as best it could. So, the process proved to be complex and very time-consuming, needing several manual interventions.

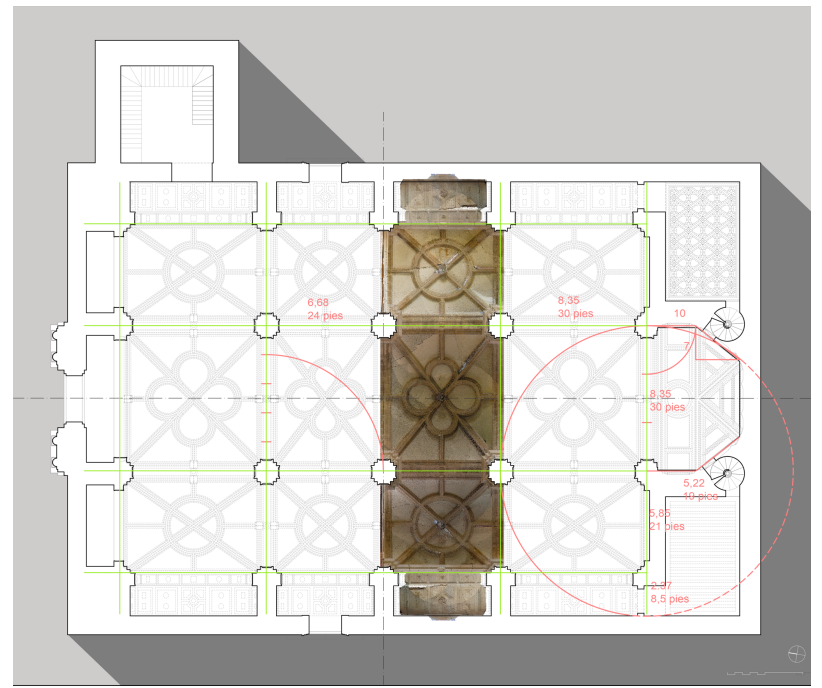

Figure 8. Floor plan with analytical drawings of the church produced using BIM.

For non-organic shapes, the adopted procedure maintains the geometric accuracy of the survey and so the reconstructed geometrical model. Revit maintains the NURBS geometry since it uses Rhino's libraries, not its own, unlike the previous methodologies. Moreover, it maintains the subdivision of elements. Elements modelled separately and included in different layers are kept in the BIM model. Revit recognizes these layers and assigns each of them to a new subcategory.

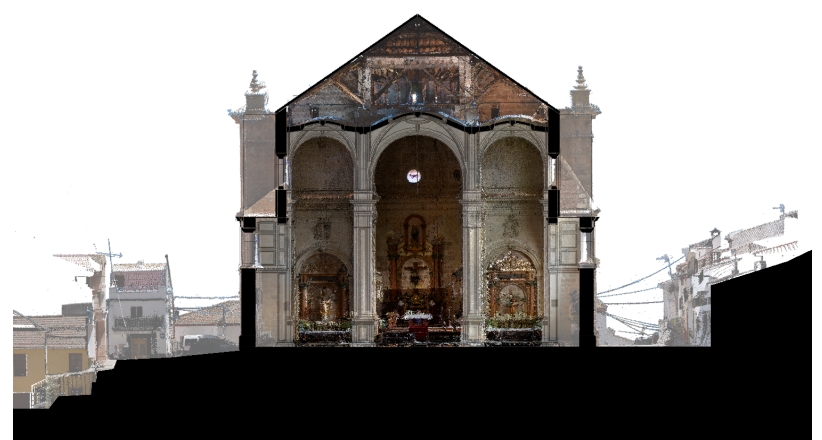

Figure 9. 3D model cross-section with solid fill and point cloud.

The procedure described ensures these three fundamental aspects:

1. Generate a reliable and detailed, digital three-dimensional (3D) model subdivided into elements.

2. Manage the digital 3D model created in BIM, supporting future building protection, conservation and restoration activities.

3. Extract and produce all kinds of $2 \mathrm{D}$ and $3 \mathrm{D}$ representations with the opportunities and advantages of BIM environments (Figure 8 and 9).

\section{REFERENCES}

Achille, C., Adami, A., Chiarini, S., Cremonesi, S., Fassi, F., Fregonese, L., Taffurelli, L., 2015. UAV-Based Photogrammetry and Integrated Technologies for Architectural ApplicationsMethodological Strategies for the After-Quake Survey of Vertical Structures in Mantua (Italy). Sensors 15, 15520-15539. doi.org/10.3390/s150715520

Acosta, E., Moya Muñoz, J., 2021. Uso conjunto de la fotogrametría terrestre y aérea para el estudio del patrimonio arquitectónico diseminado. El caso del molino de Charcón del siglo XVIII en la provincia de Écija, in: INGENIADRON 2021. LIBRO DE RESÚMENES. pp. 45-46.

Alshawabkeh, Y., Baik, A., Miky, Y., 2021. Integration of Laser Scanner and Photogrammetry for Heritage BIM Enhancement. IJGI, 10, 316. doi.org/10.3390/ijgi10050316

Apollonio, F.I., Gaiani, M., Sun, Z., 2013. 3D modeling and data enrichment in digital reconstruction of architectural heritage. Int. Arch. Photogramm. Remote Sens. Spatial Inf. Sci., XL-5/W2, 4348. doi.org/10.5194/isprsarchives-XL-5-W2-43-2013

Autodesk Development Team, 2020. Revit Support and Learn: About Cuttable Families. https://knowledge.autodesk.com/support/revit/learnexplore/caas/CloudHelp/cloudhelp/2021/ENU/RevitCustomize/files/GUID-3253EFCA-F38F-4086-9A4DC873D8D04867-htm.html (07 December 2020).

Autodesk Development Team, 2021. Revit Support and Learn: About Imported Geometry in Mass or Generic Model Families. https://knowledge.autodesk.com/support/revit/learnexplore/caas/CloudHelp/cloudhelp/2020/ENU/RevitModel/files/GUID-61BB31DA-A8AA-4F82-897F9B9F168A095B-htm.html (23 July 2021).

Baik, A., Alitany, A., Boehm, J., Robson, S., 2014. Jeddah Historical Building Information Modelling "JHBIM" - Object Library. ISPRS Ann. Photogramm. Remote Sens. Spatial Inf. Sci., II-5, 41-47. doi.org/10.5194/isprsannals-II-5-41-2014

Banfi, F., Fai, S., Brumana, R., 2017. BIM Automation: advanced modeling generative process for complex structures. ISPRS Ann. Photogramm. Remote Sens. Spatial Inf. Sci., IV-2/W2, 9-16. doi.org/10.5194/isprs-annals-IV-2-W2-9-2017

Barazzetti, L., Banfi, F., Brumana, R., Previtali, M., 2015. Creation of Parametric BIM Objects from Point Clouds Using Nurbs. Photogram Rec, 30, 339-362. doi.org/10.1111/phor.12122

Barba, S., Di Filippo, A., Cotella, V.A., Ferreyra, C., 2021. BIM Reverse Modelling Process for the Documentation of Villa Rufolo in Ravello. Disegnarecon, XIV, 26. doi.org/10.20365/DISEGNARECON.26.2021.1

Camagni, F., Colaceci, S., Russo, M., 2019. Reverse modeling of Cultural Heritage: pipeline and bottlenecks. Int. Arch. Photogramm. Remote Sens. Spatial Inf. Sci., XLII-2/W9, 197204. doi.org/10.5194/isprs-archives-XLII-2-W9-197-2019

Cardone, V., 2008. Modelli grafici dell'architettura e del territorio (nuova edizione a cura di Barba S). CUES, Salerno. 
CloudCompare Development Team, 2021. Entity Properties. CloudCompare Wiki. https://www.cloudcompare.org/doc/wiki/index.php?title=Entity properties (05 November 2021).

Davidson, S. and Iran-Nejad, E., 2020. Rhino.Inside.Revit. Core Studio $\quad$ AECTech 2020, https://www.rhino3d.com/inside/revit/beta/discover/core-studioworkshop (Last accessed: Nov 2021).

Diara, F., Rinaudo, F., 2020. Building archeology documentation and analysis through Open Source HBIM solutions via NURBS modelling. Int. Arch. Photogramm. Remote Sens. Spatial Inf. Sci., XLIII-B2-2020， 1381-1388. doi.org/10.5194/isprs-archivesXLIII-B2-2020-1381-2020

Fassi, F., Achille, C., Mandelli, A., Rechichi, F., and Parri, S., 2015. A new idea of BIM system for visualization, web sharing and using huge complex 3D models for facility management. Int. Arch. Photogramm. Remote Sens. Spatial Inf. Sci., XL-5/W4, 359-366, doi.org/10.5194/isprsarchives-XL-5-W4-359-2015

Ferreyra, C., Sanseverino, A., di Filippo, A., 2021. Image-based elaborations to improve the HBIM level of development. Building Information Modeling, Data \& Semantics, 109-120.

Gómez-Moreno, M., 1988. Diego Siloé. Edición facsímil. Universidad de Granada, Granada.

Huber, D., 2011. The ASTM E57 file format for 3D imaging data exchange, in: Beraldin, J.A., Cheok, G.S., McCarthy, M.B., Neuschaefer-Rube, U., Baskurt, A.M., McDowall, I.E., Dolinsky, M. (Eds.), Presented at the IS\&T/SPIE Electronic Imaging, San Francisco Airport, California, USA, p. 78640A. doi.org/10.1117/12.876555

López, F., Lerones, P., Llamas, J., Gómez-García-Bermejo, J., Zalama, E., 2018. A Review of Heritage Building Information Modeling (H-BIM). MTI, 2, 21. doi.org/10.3390/mti2020021

Maietti, F., Zattini, A., 2019. Documentation, analysis and representation of Modern Heritage though Building Information Modeling. Int. Arch. Photogramm. Remote Sens. Spatial Inf. Sci., XLII-2/W15, 727-734. doi.org/10.5194/isprs-archives-XLII-2W15-727-2019

Palacios Gonzálo, J.C., 2009. La cantería medieval: la construcción de la bóveda gótica española. Munilla-Lería, Madrid.

PCL contributors, 2021. Point Cloud Library (PCL) open project: Removing outliers using a StatisticalOutlierRemoval filter. Github.

https://pcl.readthedocs.io/projects/tutorials/en/latest/statistical_o utlier.html (18 September 2021).

Pepe, M., Costantino, D., Alfio, V.S., Restuccia, A.G., Papalino, N.M., 2021. Scan to BIM for the digital management and representation in 3D GIS environment of cultural heritage site. Journal of Cultural Heritage, 50, 115-125. doi.org/10.1016/j.culher.2021.05.006

Rosenthal, E.E., 1990. La Catedral de Granada: un estudio sobre el Renacimiento Español. Granada.
Rhinoceros Development Team, 2021a. Rhinoceros (v7.0) https://www.rhino3d.com/7/new/ (10 September 2021).

Rhinoceros Development Team, 2021b. Rhino.Inside.Revit plugin for Revit (v1.0): Tolerances. https://www.rhino3d.com/inside/revit/1.0/guides/rir-grasshopper (17 November 2021)

Rhinoceros Development Team, 2021c. Rhino.Inside.Revit plugin for Revit (v1.0): Rhino to Revit. https://www.rhino3d.com/inside/revit/1.0/guides/rhino-to-revit (23 September 2021)

Rocha, Mateus, Fernández, Ferreira, 2020. A Scan-to-BIM Methodology Applied to Heritage Buildings. Heritage, 3, 47-67. doi.org/10.3390/heritage3010004

Rossoni, M., Barsanti, S., Colombo, G., Guidi, G., 2019. Topology Control and Simplification of Reality-based Meshes for Finite Element Analysis, in: Proceedings of CAD'19. Presented at the CAD'19, CAD Solutions LLC, 392-396. doi.org/10.14733/cadconfP.2019.392-396

Salinas, R., 2014. 3D printing with RepRap Cookbook. Packt Publishing.

Tommasi, C., Achille, C., 2017. Interoperatiblity matter: levels of data sharing, starting from a 3D information modelling. Int. Arch. Photogramm. Remote Sens. Spatial Inf. Sci., XLII-2/W3, 623630. doi.org/10.5194/isprs-archives-XLII-2-W3-623-2017

Valle, L., Rivas, F., Cátedra, M.F., 1994. Combining the moment method with geometrical modelling by NURBS surfaces and Bezier patches. IEEE Transactions on Antennas and Propagation, 42, 373-381.

Vestartas P., Settimi A., 2020. Cockroach plugin for Rhinoceros. Food4Rhino. https://www.food4rhino.com/en/app/cockroach (25 February 2021). 